\title{
RESEARCH
}

\section{Effect of perindopril on physical function in elderly people with functional impairment: a randomized controlled trial}

\author{
Deepa Sumukadas MBBS MD, Miles D. Witham MBChB PhD, Allan D. Struthers MBChB MD, \\ Marion E.T. McMurdo MBChB MD
}

$\infty$

See related article page $89 \mathrm{I}$

\section{ABSTRACT}

Background: Physical function and exercise capacity decline with age and are a major source of disability in older people. Recent evidence suggests a potential role for the reninangiotensin system in modulating muscle function. We sought to examine the effect of the angiotensin-convertingenzyme (ACE) inhibitor perindopril on physical function in elderly people with functional impairment who had no heart failure or left ventricular systolic dysfunction.

Methods: In this double-blind randomized controlled trial, participants aged $\sigma_{5}$ years and older who had problems with mobility or functional impairment were randomly assigned to receive either perindopril or placebo for 20 weeks. The primary outcome was the change in the 6-minute walking distance over the 20 weeks. Secondary outcomes were changes in muscle function, daily activity levels, self-reported function and health-related quality of life.

Results: A total of 130 participants were enrolled in the study (mean age 78.7 , standard deviation 7.7 years); 95 completed the trial. At 20 weeks, the mean 6-minute walking distance was significantly improved in the perindopril group relative to the placebo group (mean between-group difference $31.4 \mathrm{~m}$, $95 \%$ confidence interval $[\mathrm{Cl}] 10.8$ to $51.9 \mathrm{~m} ; p=0.003$ ). There was a significant impact on health-related quality of life: although the mean score for part 1 of the EQ-5D questionnaire deteriorated over time in the placebo group, quality of life was maintained in the perindopril group, for a betweengroup difference of $0.09(p=0.046)$. There were no significant differences between the 2 groups in the other outcomes.

Interpretation: Use of the ACE inhibitor perindopril improved exercise capacity in functionally impaired elderly people who had no heart failure and maintained healthrelated quality of life. The degree of improvement was equivalent to that reported after 6 months of exercise training. (International Standard Randomised Controlled Trial Register no. ISRCTN67679521).

Une version française de ce résumé est disponible à l'adresse www.cmaj.ca/cgi/content/full/177/8/867/DCI

CMAJ 2007;177(8):867-74
A decline in physical function with age is strongly associated with disability in later life. Although regular exercise has been shown to increase muscle strength and to slow functional decline, the majority of elderly people are sedentary and either unwilling or simply unable to contemplate adequate exercise participation. Alternative strategies to improve physical function are required.

Several strands of evidence suggest a possible role for angiotensin-converting-enzyme (ACE) inhibitors in improving physical function in elderly people. First, ACE inhibitors improve endothelial function and may improve muscle function by increasing muscle blood flow and glucose delivery. ${ }^{1}$ Second, an observational study involving elderly women with hypertension reported that ACE inhibitors slowed the decline in physical function and muscle strength when compared with other antihypertensive agents. ${ }^{2}$ Third, people with the II genotype of the ACE gene have low ACE activity and have been found to have an enhanced endurance performance and an anabolic response to exercise training. ${ }^{3}$ Fourth, use of an ACE inhibitor in a randomized placebo-controlled trial resulted in a significant improvement in exercise capacity among elderly patients with heart failure due to left ventricular systolic dysfunction. ${ }^{4}$ Although this effect may have been the result of improved cardiac function, ACE inhibitors may have direct effects on skeletal muscle. We therefore sought to examine the effect of the ACE inhibitor perindopril on physical function in functionally impaired elderly people who had no heart failure or left ventricular systolic dysfunction.

\section{Methods}

\section{Study design and participants}

This was a prospective, parallel-group, double-blind, randomized, placebo-controlled trial conducted between August 2003 and March 2006. Participants were recruited from among patients in the Medicine for the Elderly services in Tayside, Scotland, and from among patients attending other NHS services in Tayside. Patients aged 65 years or more with self-

From the Section of Ageing and Health (Sumukadas, Witham, McMurdo) and the Department of Clinical Pharmacology (Struthers), University of Dundee, Dundee, UK 
reported problems with mobility or functional activities of daily living were eligible. We excluded patients who had a clinical diagnosis of heart failure (according to the 2002 European Society of Cardiology guidelines ${ }^{5}$ ), left ventricular systolic dysfunction, significant aortic stenosis (peak pressure gradient $>30 \mathrm{~mm} \mathrm{Hg}$ ), systolic blood pressure below $90 \mathrm{~mm} \mathrm{Hg}$, symptomatic orthostatic hypotension, serum creatinine level above $200 \mu \mathrm{mol} / \mathrm{L}$, serum potassium level above $5.5 \mathrm{mmol} / \mathrm{L}$ or Mini-Mental State Examination score below I5 (of 30). We also excluded patients who were wheelchair bound, were already receiving an ACE inhibitor or angiotensin II receptor blocker, or had a previous adverse reaction to either drug.

At an initial screening visit, participants underwent a clinical assessment and an assessment of left ventricular systolic function by means of echocardiography. Assessment of left ventricular function by this method has been found to have good agreement with other validated methods of estimating such function. ${ }^{6}$

All participants provided written informed consent. The study was approved by the Tayside Committee on Medical Research Ethics and was in accord with the World Medical Association's Declaration of Helsinki (www.wma.net/e/policy/bz.htm).

\section{Randomization}

Tayside Pharmaceuticals, Dundee, UK, performed the randomization, to ensure allocation concealment, using a computer-generated random-number table. The perindopril tablets were encapsulated to make them appear identical to the placebo. Each medication bottle was labelled with a number corresponding to the patient's study number. No labelling corresponding to allocation group appeared on the medication. The randomization code (patient number v. allocation) was held by Tayside Pharmaceuticals, which encapsulated and packaged the medication for the trial. The researcher responsible for enrolling patients and distributing medication had no access to the randomization code. Therefore, both researcher and participant were blind to the treatment allocation. The initial dose of $2 \mathrm{mg}$ of perindopril daily or placebo was increased to $4 \mathrm{mg}$ of perindopril daily or placebo after 2 weeks if tolerated. Treatment continued for 20 weeks.

\section{Outcome measures}

All outcomes were assessed at baseline and at Io and 20 weeks after randomization by a single researcher (D.S.), who was blind to treatment allocation. The primary outcome was the change in 6-minute walking distance over the 20 weeks. This walking test is a safe, reliable and repeatable measure of functional status in elderly people ${ }^{7}$ and is often used to measure the effect of interventions. ${ }^{8-10}$ Participants walked for 6 minutes over a $25-\mathrm{m}$ course using their customary walking aids and were allowed to rest if required. Standardized encouragement was given. Although practice runs of the walking test are recommended to reduce the impact of a learning effect, this was not practical in our group of participants with mobility impairment because they tired easily.

The secondary outcomes were changes in muscle function, daily activity levels, self-reported function and quality of life, as measured using the following tests. The sit-to-stand test, a simple, reproducible test of muscle strength in elderly people, measures the time taken to get up from a chair and sit down again to times. ${ }^{11}$ The timed up-and-go test measures functional mobility in elderly people $e^{12,13}$ by recording the time taken to rise from a chair, walk $3 \mathrm{~m}$ and return to sit in the chair. This test has been found to have good intra-rater reliability. ${ }^{14} \mathrm{An}$ accelerometer (RT3 Tri-axial Research Tracker; Stayhealthy Inc., Monrovia, Calif.) was worn by participants at the hip for a week during waking hours to measure daily activity counts. Tri-axial accelerometry has been shown to reflect directly observed daily activity in elderly people. ${ }^{15}$ The Nottingham Extended Activities of Daily Living questionnaire, initially designed for patients with stroke, has been used in different settings and measures self-reported function and disability. ${ }^{16,17}$ The EuroQol EQ- 5 D is a selfadministered 2-part questionnaire on health-related quality of life. ${ }^{18}$ The first part contains questions that pertain to 5 domains: mobility, self-care, usual activities, pain/discomfort and anxiety/depression. Responses are recorded as a 5-digit code, which is then converted to a score from -0.59 to I with the use of tables of values weighted by the EuroQol Group. The second part is a $20-\mathrm{cm}$ vertical visual analogue scale that patients use to rate their overall health state, from o (worst imaginable health state) to Ioo (best imaginable health state). Participants completed the 2 parts during an interview with the researcher (D.S.).

Blood samples were obtained to measure serum creatinine, urea and electrolyte levels at baseline and at 2, 5, Io and 20 weeks. Samples were sent to the Department of Biochemical Medicine at Ninewells Hospital, Dundee, and were analyzed using the Roche modular system (Roche Diagnostics, Lewes, East Sussex, UK). Echocardiography was repeated at 20 weeks to rule out the occult development of left ventricular systolic dysfunction during the study period.

\section{Statistical analysis}

Through a power calculation, we estimated that a final sample of 94 participants would give $90 \%$ power $(\alpha=0.05,2$ tailed) to detect a difference of $20 \mathrm{~m}$ in the 6 -minute walking distance, assuming a standard deviation of $30 \mathrm{~m}$. From previous studies, we anticipated a mean walking distance of $274 \mathrm{~m}^{4}{ }^{4}$ A projected sample size of $\mathrm{I} 46$ allowed for a dropout rate of $35 \%$ over the 20 -week study period.

After final data entry, the allocation code (as group A or B) was obtained and analysis completed before the treatment code was broken. Complete case analysis was primarily used (i.e., participants with missing outcome data were excluded from analysis). The change in outcome measures from baseline was normally distributed, and Student's $t$ test was used to compare differences between the treatment and control groups. To address any effect of regression to the mean, we analyzed the percentage change in 6-minute walking distance and performed an analysis of covariance incorporating the baseline distance as a covariate. For multivariable analysis, we used the baseline data included in Table I as covariates in a general linear model to estimate marginal means for the perindopril and placebo groups. The F test was then used to compare significance between the estimated marginal means. To mitigate the effect of the dropouts confounding the results, we carried out betweengroup analysis using io multiple imputations for noncompleters. We performed best- and worst-case analyses using best 
Table 1: Demographic and baseline clinical characteristics of elderly patients with functional impairment enrolled in the trial

\begin{tabular}{|c|c|c|c|c|}
\hline \multirow[b]{2}{*}{ Characteristic } & \multicolumn{2}{|c|}{ Included in randomization } & \multicolumn{2}{|c|}{ Completed trial } \\
\hline & $\begin{array}{l}\text { Perindopril group } \\
\quad n=65\end{array}$ & $\begin{array}{l}\text { Placebo group } \\
\quad n=65\end{array}$ & $\begin{array}{l}\text { Perindopril group } \\
\quad n=45\end{array}$ & $\begin{array}{l}\text { Placebo group } \\
\quad n=50\end{array}$ \\
\hline Age, yr, mean (SD) & $78.6(6.1)$ & $78.7(7.1)$ & $78.7(6.2)$ & $78.3(6.9)$ \\
\hline Male sex, no. (\%) & $17(26)$ & $21(32)$ & $13(29)$ & $16(32)$ \\
\hline \multicolumn{5}{|l|}{ Smoking status, no. (\%) } \\
\hline Current smoker & $10(15)$ & $8(12)$ & $6(13)$ & $7(14)$ \\
\hline Former smoker & $25(38)$ & $23(35)$ & $16(36)$ & $19(38)$ \\
\hline Never smoked & $30(46)$ & $34(52)$ & $23(51)$ & $24(48)$ \\
\hline \multicolumn{5}{|l|}{ Medical history, no. (\%) } \\
\hline Falls & $9(14)$ & $3(5)$ & $6(13)$ & $2(4)$ \\
\hline Hypertension & $37(57)$ & $26(40)$ & $27(60)$ & $21(42)$ \\
\hline Ischemic heart disease & $13(20)$ & $13(20)$ & $9(20)$ & $8(16)$ \\
\hline Peripheral vascular disease & $9(14)$ & 3 (5) & $7(16)$ & $1 \quad(2)$ \\
\hline Stroke & $4 \quad(6)$ & $6 \quad(9)$ & $4 \quad(9)$ & $3(6)$ \\
\hline Diabetes mellitus & $1(2)$ & $5 \quad(8)$ & $1(2)$ & $3(6)$ \\
\hline Parkinson's disease & $7(11)$ & $7(11)$ & $5(11)$ & $5(10)$ \\
\hline \multicolumn{5}{|l|}{ Medications } \\
\hline Total no. of drugs prescribed, mean (SD) & $5.5(2.7)$ & $4.3(3.7)$ & $5.3(2.6)$ & $4.2(2.6)$ \\
\hline \multicolumn{5}{|l|}{ Diuretic, no. (\%) } \\
\hline Loop & $11(17)$ & $8(12)$ & $9(20)$ & $6(12)$ \\
\hline Thiazide & $16(25)$ & $6 \quad(9)$ & $13(29)$ & $6(12)$ \\
\hline Potassium sparing & $5(8)$ & $2(3)$ & 4 (9) & $2(4)$ \\
\hline Spironolactone & $2(3)$ & 0 & $1(2)$ & 0 \\
\hline$\beta$-Blocker, no. (\%) & $11(17)$ & $12(18)$ & $9(20)$ & $10(20)$ \\
\hline Calcium antagonist, no. (\%) & $5(8)$ & 3 (5) & $4 \quad(9)$ & $316)$ \\
\hline Nitrate, no. (\%) & $9(14)$ & 6 (9) & $5(11)$ & $5(10)$ \\
\hline Statin, no. (\%) & $10(15)$ & $11(17)$ & $7(16)$ & $7(14)$ \\
\hline \multicolumn{5}{|l|}{ Walking aid used, no. (\%) } \\
\hline Stick & $27(42)$ & $24(37)$ & $19(42)$ & $18(36)$ \\
\hline Zimmer frame & 1 (2) & $2(3)$ & $1(2)$ & $1(2)$ \\
\hline Triwheel walker & $3(5)$ & $6 \quad(9)$ & $2(4)$ & $4(8)$ \\
\hline \multicolumn{5}{|l|}{ Blood pressure, mm Hg, mean (SD) } \\
\hline Systolic & $146.4(15.9)$ & $144.6(14.8)$ & $146.2(16.1)$ & $144.0(15.3)$ \\
\hline Disatolic & $76.5 \quad(8.9)$ & $79.9 \quad(8.5)$ & $77.2 \quad(8.9)$ & $80.3(7.9)$ \\
\hline Serum potassium level, mmol/L, mean (SD) & $4.2(0.4)$ & $4.3(0.4)$ & $4.1 \quad(0.4)$ & $4.3(0.4)$ \\
\hline Serum creatinine level, $\mu \mathrm{mol} / \mathrm{L}$, mean (SD) & $95.8(20.8)$ & $95.0(22.1)$ & $95.2(18.9)$ & $94.5(22.4)$ \\
\hline $\begin{array}{l}\text { B-type natriuretic peptide level, pmol/L, } \\
\text { median (Q1-Q3) }\end{array}$ & $18.1(9.6-34.4)$ & $17.1(9.1-27.6)$ & $18.1(10.7-33.7)$ & $20.3(9.3-28.4)$ \\
\hline $\begin{array}{l}\text { Calculated glomerular filtration rate, } \mathrm{mL} / \mathrm{min} \\
\text { (Cockcroft Gault formula), mean (SD) }\end{array}$ & $46.8(14.3)$ & $49.7(18.0)$ & $48.5(13.4)$ & $50.1(17.2)$ \\
\hline ACE genotype II:ID:DD, \% & $26: 51: 23$ & $26: 57: 17$ & $27: 53: 20$ & $28: 54: 18$ \\
\hline MMSE score, median (Q1-Q3) & $29(27-30)$ & $29(28-30)$ & $29(28-30)$ & $29(29-30)$ \\
\hline Weight, kg, mean (SD) & $64.5(14.1)$ & $65.6 \quad(12.8)$ & $67.1(14.9)$ & $66.1 \quad(12.4)$ \\
\hline 6-minute walking distance, $\mathrm{m}$, mean (SD) & $294.0(98.9)$ & $303.9(109.9)$ & $292.7(100.3)$ & $316.7(106.8)$ \\
\hline Sit-to-stand time, s, median (Q1-Q3) & $36.8(29.3-47.2)$ & $37.8(30.6-47.3)$ & $37.1(30.2-48.4)$ & $37.2(29.9-46.2)$ \\
\hline Timed up-and-go time, s, median (Q1-Q3) & $13.0(10.5-17.2)$ & $12.7 \quad(9.8-16.4)$ & $13.5(10.3-17.2)$ & $12.6(9.7-15.8)$ \\
\hline NEADL score (0 to 66$)$, mean (SD) & $47.5(10.3)$ & $47.6(10.7)$ & $47.6 \quad(9.8)$ & $49.0 \quad(9.9)$ \\
\hline \multicolumn{5}{|l|}{ Quality of life (EQ-5D quesitonnaire) } \\
\hline Part 1, 5-domain score (-0.59 to 1.0$)$, median (Q1-Q3) & $0.69(0.59$ to 0.81$)$ & 0.73 (0.62 to 0.85$)$ & 0.69 (0.59 to 0.82$)$ & $0.73(0.62$ to 0.88$)$ \\
\hline Part 2, visual analogue scale (0 to 100$)$, mean (SD) & $68.0(16.8)$ & $69.6(15.6)$ & $69.7(17.4)$ & $70.5(15.1)$ \\
\hline Activity count, no. per day, mean (SD)* & $98008(46756)$ & $108514(53865)$ & 97428 (44 977) & $115871(53930)$ \\
\hline
\end{tabular}

Note: $\mathrm{SD}=$ standard deviation, $\mathrm{ACE}=$ angiotensin-converting enzyme, MMSE $=$ Mini-Mental State Examination, NEADL = Nottingham Extended Activities of Daily Living, EQ-5D = EuroQol 5-domain questionnaire on health-related quality of life (see Methods for details).

*Measured with a tri-axial accelerometer worn during waking hours (see Methods for details). 
improvement and worst deterioration, respectively, for missing values. We conducted a post-hoc subgroup analysis to generate a hypothesis regarding the mechanisms behind the change in the primary outcome. For this analysis, we divided participants into subgroups using major baseline data. The between-group difference in the change in 6-minute walking distance was analyzed for each subgroup using Student's $t$ test. Fixed-effect comparison between subgroups was then performed.

\section{Results}

A total of 255I patients were assessed for eligibility in the study. Of these, 1929 were excluded because they did not meet

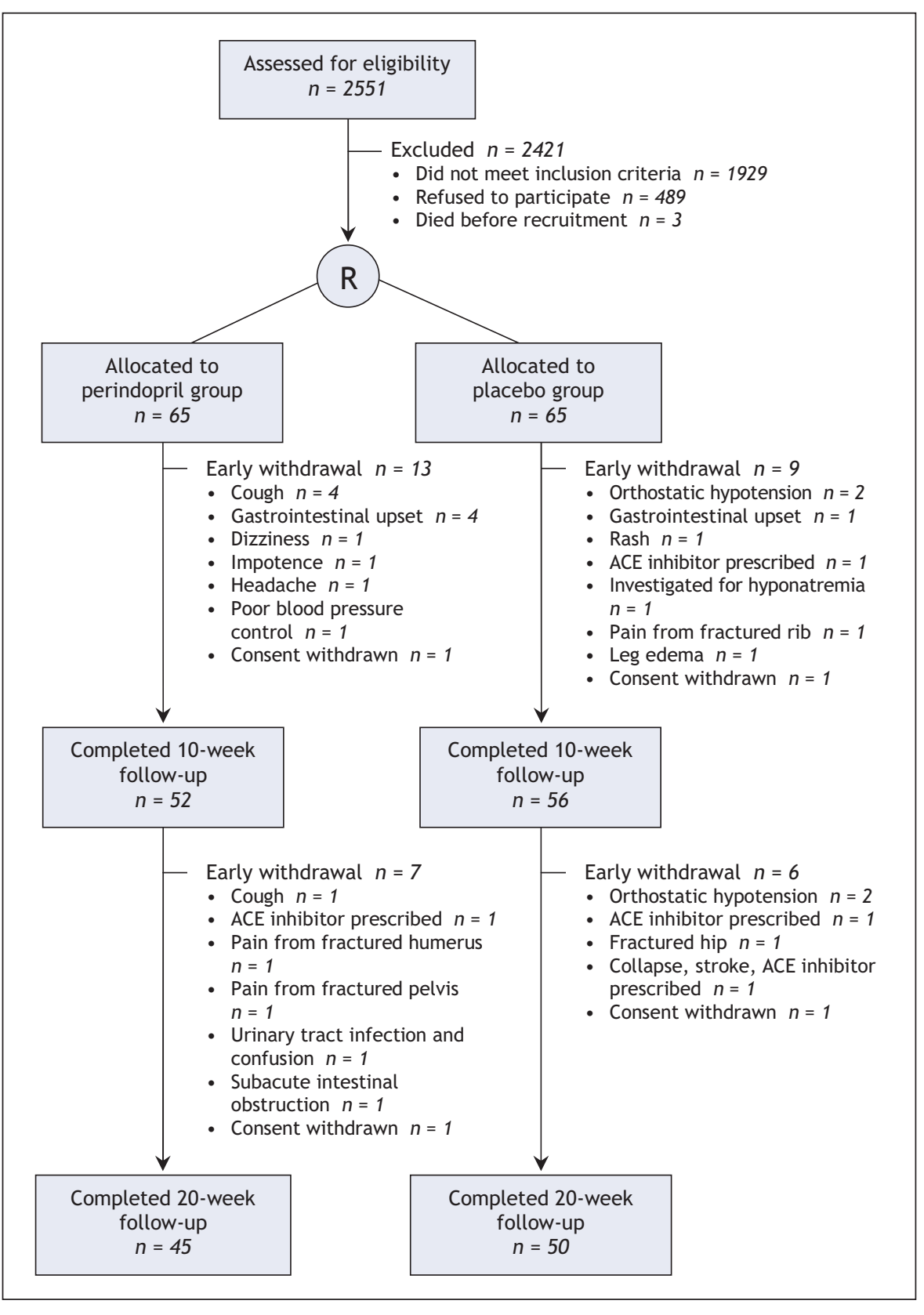

Figure 1: Flow of patients through the study. $\mathrm{R}=$ randomization, $\mathrm{ACE}=$ angiotensinconverting enzyme. the inclusion critiera (892 were taking an ACE inhibitor or angiotensin II receptor blocker, 347 had left ventricular systolic dysfunction, 283 had symptomatic orthostatic hypotension, 58 had a serum creatinine level above $200 \mu \mathrm{mol} / \mathrm{L}, 49$ had significant aortic stenosis, 130 had another contraindication to ACE inhibitor therapy, 136 were wheelchair bound, and 180 had a Mini-Mental State Examination score below I5), 489 refused to participate, and 3 died before recruitment. Of the remaining I30 participants who were enrolled, 95 (73\%) completed the trial (Figure I). The baseline characteristics of the I30 participants are shown in Table I alongside the characteristics of the 95 who completed the study.

The dose of medication was not increased at 2 weeks for 6 patients. In the perindopril group, reasons for this were an increase in orthostatic hypotension $(n=\mathrm{I})$ and a fall in systolic blood pressure to less than Ioo $\mathrm{mm} \mathrm{Hg}$ with the initial dose $(n=\mathrm{I})$. In the placebo group, reasons were an increase of at least $30 \%$ in the serum creatinine level $(n=\mathrm{I})$, an increase in the potassium level $(n=\mathrm{I})$, an increase in orthostatic hypotension $(n=\mathrm{I})$ and a fall in systolic blood pressure to less than Ioo $\mathrm{mm} \mathrm{Hg}$ with the initial dose $(n=\mathrm{I})$.

\section{Primary outcome}

Figure 2 shows the change in 6-minute walking distance from baseline in the perindopril and placebo groups at io and 20 weeks. At the end of ro weeks, the difference between the 2 groups was not significant $(p=0.19)$. At the end of 20 weeks, the change in walking distance from baseline was significantly greater in the treatment group than in the placebo group (mean betweengroup difference $3 \mathrm{I} .4 \mathrm{~m}, 95 \% \mathrm{CI}$ io. 8 to $5 \mathrm{I} .9 \mathrm{~m} ; p=0.003)$. Additional analysis in which participants with a cough were excluded to eliminate possible observer bias still showed a significant difference between the 2 groups (mean betweengroup difference $3 \mathrm{I} .7 \mathrm{~m}, 95 \% \mathrm{CI}$ I0.5 to $52.9 \mathrm{~m} ; p=0.004)$.

The difference between the 2 groups in the change in 6-minute walking distance remained significant in various sensitivity analyses (Table 2 ). In the multivariable analysis, which incorporated all of the baseline variables listed in Table I, the statistical significance of the between-group difference (Table 2) suggested that the randomization was robust. Using multiple imputation for missing values due to dropouts, we found that the perindopril group had a mean 6-minute walking distance of 


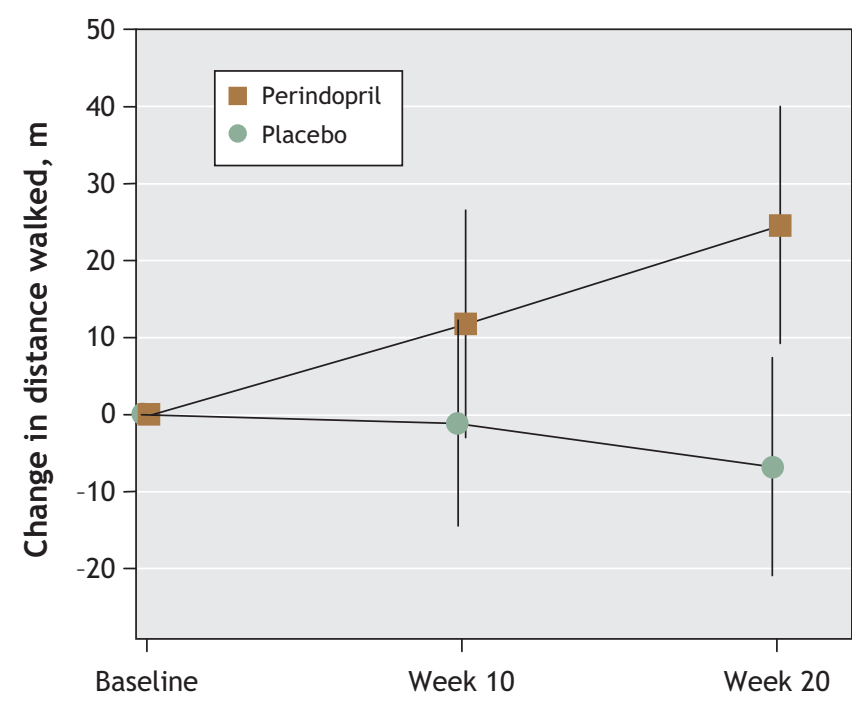

Figure 2: Change in 6-minute walking distance in perindopril and placebo groups from baseline to 10 weeks and 20 weeks.

$30.5 \mathrm{~m}$ (95\% CI 17.7 to 43.3 ) relative to the placebo group. The mean distance in the treatment group relative to the placebo group was $34.0 \mathrm{~m}$ (95\% CI 7.3 to $60.8, p=0.013$ ) in the best-case analysis for missing values and $\mathrm{I} 2.3 \mathrm{~m}(95 \% \mathrm{CI}$ $-\mathrm{I} 2.3$ to $38.7, p=0.36$ ) in the worst-case analysis for missing values. The results of the post-hoc subgroup analysis of major baseline data are presented in Table 3 .

\section{Secondary outcomes}

The change in secondary outcome measures from baseline to 20 weeks are provided in Table 4 . There was a nonsignificant improvement in the times for the sit-to-stand and timed upand-go tests in the perindopril group relative to the placebo group. There was no significant difference between the 2 groups in daily activity counts. The mean score for part $\mathrm{I}$ of the EQ-5D questionnaire improved significantly in the perindopril group relative to the placebo group. The change in the visual analogue scale ratings in part 2 of the EQ-5D did not differ significantly between the 2 groups, nor did the change in the Nottingham Extended Activities of Daily Living scale.

\section{Other outcomes}

At 20 weeks, the mean systolic blood pressure was $4 \mathrm{~mm} \mathrm{Hg}$ lower and $3 \mathrm{~mm} \mathrm{Hg}$ higher than baseline values in the perindopril and placebo groups, respectively, for a significant between-group difference of $-7 \mathrm{~mm} \mathrm{Hg}$ (95\% CI -I4.I to 0.5 $\mathrm{mm} \mathrm{Hg} ; \mathrm{p}=0.07)$. The mean diastolic blood pressure was lower than baseline values by $2 \mathrm{~mm} \mathrm{Hg}$ and $\mathrm{I} \mathrm{mm} \mathrm{Hg}$ in the perindopril and placebo groups, respectively; the betweengroup difference was not significant $(p=0.53)$. The change in the degree of orthostatic hypotension did not differ significantly between the 2 groups $(p=0.46)$.

Compared with the placebo group, the perindopril group had significant increases in the serum potassium level (by $0.2 \mathrm{mmol} / \mathrm{L}, 95 \% \mathrm{CI}$ o.I to $0.3 \mathrm{mmol} / \mathrm{L} ; p=0.002)$, urea level (by I mmol/L, 95\% CI 0.2 to I.9 mmol/L; $p=0.02$ ) and creatinine level (by $6.7 \mu \mathrm{mol} / \mathrm{L}, 95 \%$ CI 2.I to II.2 $\mu \mathrm{mol} / \mathrm{L} ; p=$ $0.004)$. The serum creatinine level rose by more than $25 \mu \mathrm{mol} / \mathrm{L}$ from baseline in 3 patients in the perindopril group and in I patient in the placebo group at 20 weeks; none of the levels rose above $200 \mu \mathrm{mol} / \mathrm{L}$. Repeat echocardiography at 20 weeks showed that left ventricular systolic dysfunction had not developed in any of the participants during the study period.

None of the participants underwent any exercise intervention during the study period. Drugs prescribed during the study period included diuretics (3 participants in each group), statins ( $\mathrm{I}$ in each group), $\beta$-blockers ( $\mathrm{I}$ in each group), and calcium and vitamin D supplements ( 2 in the placebo group). Four of the participants ( $\mathrm{I}$ in the perindopril group and 3 in the placebo group) were prescribed an ACE inhibitor and were withdrawn from the study.

\section{Adverse events}

Five of the participants in the perindopril group were admitted to hospital: I had a syncopal attack, I had a fractured humerus from a fall, I had a rectal prolapse, I underwent elective cataract

Table 2: Differences between perindopril and placebo groups in change in 6-minute walking distance from baseline to 20 weeks in various analyses

\begin{tabular}{|c|c|c|c|c|}
\hline \multirow[b]{2}{*}{ Analysis } & \multicolumn{2}{|c|}{$\begin{array}{l}\text { Change in distance } \\
\text { from baseline, } \mathrm{m}\end{array}$} & \multirow[b]{2}{*}{$\begin{array}{l}\text { Between-group difference, } \\
\mathrm{m} \text {, mean }(95 \% \mathrm{Cl})^{*}\end{array}$} & \multirow[b]{2}{*}{$p$ value } \\
\hline & $\begin{array}{l}\text { Perindopril } \\
\quad n=45\end{array}$ & $\begin{array}{c}\text { Placebo } \\
n=50\end{array}$ & & \\
\hline Complete case analysis $\dagger$ & 24.6 & -6.8 & 31.4 (10.8 to 51.9$)$ & 0.003 \\
\hline$\%$ change from baseline distance & 11.0 & -0.3 & 11.3 (3.3 to 19.4$)$ & 0.006 \\
\hline $\begin{array}{l}\text { Covariate adjusted for baseline } \\
\text { 6-minute walking distance }\end{array}$ & 22.9 & -5.3 & 28.2 (8.1 to 48.3$)$ & 0.006 \\
\hline $\begin{array}{l}\text { Multivariable analysis incorporating } \\
\text { all baseline data in Table } 1\end{array}$ & 30.4 & -10.3 & 40.7 (15.9 to 65.6$)$ & 0.002 \\
\hline Multiple imputation analysis & NA & NA & 30.5 (17.7 to 43.3$)$ & $<0.001$ \\
\hline
\end{tabular}

Note: $\mathrm{Cl}=$ confidence interval, $\mathrm{NA}=$ not available.

*Unless stated otherwise.

†Participants with missing outcome data were excluded from the analysis. 
surgery, and I was admitted twice because of pancreatitis and later subacute intestinal obstruction. Four in the placebo group were admitted to hospital: I had a hip fracture from a fall, I experienced a stroke, I underwent elective trigeminal nerve release, and I was admitted twice because of chest infection and later cellulitis. The difference in the number of hospital admissions between the 2 groups was not significant $(p=0.45)$.

Ten falls occurred involving 8 participants in the perindopril group; fractures occurred in 3 (humerus in I, pelvis in I and wrist in I). Eighteen falls occurred involving Io participants in the placebo group; fractures occurred in 2 (hip in I and ribs in the other). The number of falls during the study period did not differ significantly between the 2 groups $(p=0.14)$. Seven par- ticipants in the perindopril group and 3 in the placebo group had gastrointestinal disturbances; this difference was not significant $(p=0.12)$. Nine participants had a cough and I experienced a collapse in the perindopril group. Adverse events that led to withdrawal from the study are shown in Figure I (the complete list of adverse events is in Appendix I, available online at www.cmaj.ca/cgi/content/full/177/8/867/DC2).

\section{Interpretation}

Our results showed that, compared with placebo, perindopril significantly improved the 6-minute walking distance by more than $30 \mathrm{~m}$ on average. A $20-\mathrm{m}$ change in this distance is re-

Table 3: Subgroup analysis of differences between perindopril and placebo groups in change in 6-minute walking distance from baseline to 20 weeks

\begin{tabular}{|c|c|c|c|}
\hline Subgroup & $\begin{array}{l}\text { Between-group difference in } \\
\text { change in distance from } \\
\text { baseline, } \mathrm{m} \text {, mean }(95 \% \mathrm{Cl})\end{array}$ & $p$ value & $\begin{array}{l}\text { Comparison between } \\
\text { subgroups, } p \text { value }\end{array}$ \\
\hline \multicolumn{4}{|l|}{ Sex } \\
\hline Female & $21.5 \quad(-5.0$ to 48.1$)$ & 0.11 & \multirow{2}{*}{0.16} \\
\hline Male & $53.8 \quad(22.6$ to 85.1$)$ & 0.001 & \\
\hline \multicolumn{4}{|l|}{ Diuretic use } \\
\hline No & $28.1 \quad(-0.4$ to 56.5$)$ & 0.053 & \multirow{2}{*}{0.63} \\
\hline Yes & $43.8 \quad(8.8$ to 78.8$)$ & 0.015 & \\
\hline \multicolumn{4}{|c|}{ Peripheral vascular disease } \\
\hline Yes & 155.0 (26.1 to 283.9 ) & 0.03 & \multirow{2}{*}{0.021} \\
\hline No & $28.6 \quad$ (7.4 to 49.9$)$ & 0.009 & \\
\hline \multicolumn{4}{|c|}{ Use of walking aid } \\
\hline No & $18.2(-11.9$ to 48.2$)$ & 0.23 & \multirow{2}{*}{0.18} \\
\hline Yes & 46.2 (17.4 to 75.1$)$ & 0.002 & \\
\hline \multicolumn{4}{|l|}{ HOPE criteria* } \\
\hline Present & $43.3 \quad(0.9$ to 85.6$)$ & 0.046 & \multirow{2}{*}{0.59} \\
\hline Absent & $31.1 \quad$ (8.4 to 53.8$)$ & 0.008 & \\
\hline \multicolumn{4}{|l|}{ Age, yr } \\
\hline$<80$ & 45.4 (22.2 to 68.6$)$ & $<0.001$ & \multirow{2}{*}{0.08} \\
\hline$\geq 80$ & 7.1 (-33 to 47.3$)$ & 0.72 & \\
\hline \multicolumn{4}{|l|}{ ACE genotype } \\
\hline II & $26.9(-20.5$ to 74.4$)$ & 0.25 & \multirow{3}{*}{0.70} \\
\hline ID & 39.2 (12.4 to 66.1$)$ & 0.005 & \\
\hline DD & $17.0(-29.8$ to 63.8$)$ & 0.45 & \\
\hline \multicolumn{4}{|c|}{$\begin{array}{l}\text { Glomerular filtration rate, } \dagger \\
\mathrm{mL} / \mathrm{min}\end{array}$} \\
\hline$<60$ & $39 \quad(13.7$ to 64.5$)$ & 0.003 & \multirow{2}{*}{0.20} \\
\hline$\geq 60$ & $8.6(-25.9$ to 43.1$)$ & 0.61 & \\
\hline \multicolumn{4}{|l|}{ Hypertension } \\
\hline Yes & 41.5 (14.2 to 68.7$)$ & 0.004 & \multirow{2}{*}{0.52} \\
\hline No & $27.8 \quad(-4.4$ to 60.0$)$ & 0.09 & \\
\hline \multicolumn{4}{|c|}{ Activity countsł } \\
\hline Below median & $41.6 \quad(13.9$ to 69.3$)$ & 0.004 & \multirow{2}{*}{0.86} \\
\hline Above median & $22.4(-11.5$ to 56.4$)$ & 0.19 & \\
\hline
\end{tabular}

Note: $\mathrm{Cl}=$ confidence interval, $\mathrm{ACE}=$ angiotensin-converting enzyme.

*HOPE (Heart Outcomes Prevention Evaluation) trial criteria for risk of cardiovascular events: history of stroke, ischemic heart disease,

peripheral vascular disease or diabetes mellitus plus a cardiovascular risk factor (smoking, high lipid levels, hypertension, microalbuminuria). ${ }^{19}$

†Calculated using the Cockcroft Gault formula.

$\neq$ Measured with a tri-axial accelerometer worn during waking hours (see Methods for details). 
garded as the minimum clinically important change in physical performance in elderly people. ${ }^{20}$ The degree of improvement observed in our study is comparable to the improvement seen after 6 months of exercise. ${ }^{21,22}$ The use of perindopril in our study resulted in improved exercise capacity over the 20 weeks rather than merely arresting decline. The absence of practice runs for the 6-minute walking test was unlikely to have affected the results, because any learning effect would have occurred in both the treatment and the placebo groups. Perindopril was well tolerated, as evidenced by similar dropout rates in the 2 groups. The dropout rate was lower than the anticipated $35 \%$, which thereby reduced the need for recruitment from 146 to I30 participants in order to achieve our target sample of 94 participants to complete the study. Reports of cough may have led to some loss of randomization integrity; however, our analysis that excluded those with a cough still showed a significant improvement in the 6-minute walking distance in the perindopril group relative to the placebo group.

The improvement in exercise capacity was associated with a significant impact on health-related quality of life. Although the mean score for part I of the EQ-5D deteriorated over time in the placebo group by more than the minimal clinically important difference of $0.074,{ }^{9}$ quality of life was maintained in the perindopril group. A fall in the EQ-5D score of 0.05 has been found to be associated with an increase in 5-year mortality. ${ }^{23}$ The improvement in the EQ-5D score in the perindopril group was not matched by a similar improvement in the EQ${ }_{5} \mathrm{D}$ visual analogue scale, however. This is in keeping with findings from other studies that found the EQ-5D visual analogue scale to be less sensitive to change than part I of the EQ${ }_{5} \mathrm{D} .{ }^{24} \mathrm{We}$ also found no effect of perindopril on the Nottingham Extended Activities of Daily Living scores. Even studies of exercise involving elderly people have shown no benefit using questionnaires on self-reported function and disability. ${ }^{25}$

Many physicians are concerned that ACE inhibitors may aggravate the risk of falls in elderly people by causing postural hypotension. Interestingly, we found a trend toward a reduction in the number of falls in the perindopril group relative to the placebo group over the study period. However, we excluded patients with symptomatic hypotension. Although it is possible that ACE inhibitors may reduce falls through improvement in physical function, studies specifically designed to evaluate this are required.

The positive influence of ACE inhibition on physical function in elderly people may be due to a number of potential mechanisms. ACE inhibitors increase nitric oxide production. ${ }^{1}$ Nitric oxide has been found to have a facilitatory action on the contractility of skeletal muscle at physiologic pressures of oxygen and to increase the number of sarcomeres and walking speed. ${ }^{26-28} \mathrm{~A}$ cross-sectional study involving elderly people without heart failure found that those taking an ACE inhibitor had increased muscle bulk compared with those taking another antihypertensive agent. ${ }^{29}$ In another study, ACE inhibition in patients with congestive heart failure was associated with increased exercise capacity and a shift in type of muscle fibre from type II to type I. ${ }^{30}$ Our findings of an increase in exercise capacity may also reflect a shift toward type I muscle fibre.

A direct influence of ACE inhibitors on cardiac function cannot be ruled out. In a randomized placebo-controlled trial, the ACE inhibitor ramipril was found to reduce left ventricular mass and preserve left ventricular function in patients without left ventricular systolic dysfunction. ${ }^{31}$ In the early stages of cardiac pressure overload, skeletal muscle dysfunction develops, and ACE inhibitors prevent this mainly by limiting the loss of cross bridges. ${ }^{32} \mathrm{~A}$ similar action of ACE inhibitors on skeletalmuscle cross bridges in elderly people may explain our results. It has been shown that cardiovascular problems are associated with poor physical function. ${ }^{33}$ ACE inhibitors may improve physical function by improving vascular function. Walking distance was found to improve in patients with peripheral vascular disease given ramipril. ${ }^{34}$ We conducted a post-hoc subgroup analysis of major baseline factors that could affect the change in 6-minute walking distance between the 2 groups. Although the results of this analysis showed that participants under 80 years of age and those with peripheral vascular disease tended to show more benefit from perindopril than their counterparts (Table 3), this should be inferred with caution and only considered as hypothesis generating.

Table 4: Change in secondary outcome measures from baseline to 20 weeks in perindopril and placebo groups

\begin{tabular}{|c|c|c|c|c|}
\hline \multirow[b]{2}{*}{ Outcome } & \multicolumn{2}{|c|}{ Change from baseline } & \multirow[b]{2}{*}{$\begin{array}{l}\text { Between-group difference, } \\
\text { mean }(95 \% \mathrm{Cl})\end{array}$} & \multirow[b]{2}{*}{$p$ value } \\
\hline & $\begin{array}{l}\text { Perindopril } \\
\quad n=45\end{array}$ & $\begin{array}{c}\text { Placebo } \\
n=50\end{array}$ & & \\
\hline Sit-to-stand test, $\mathrm{s}^{*}$ & -2.7 & 0.4 & $-3.1(-7.5$ to 1.3$)$ & 0.17 \\
\hline Timed up-and-go test, $\mathrm{s}^{*}$ & -0.6 & 0.7 & $-1.3(-2.8$ to 0.2$)$ & 0.08 \\
\hline NEADL score & 0.7 & -1.9 & $2.6(-1.1$ to 3.6$)$ & 0.29 \\
\hline \multicolumn{5}{|l|}{$\begin{array}{l}\text { Healtlh-related quality of life } \\
\text { (EQ-5D questionnaire) }\end{array}$} \\
\hline Part 1, 5-domain score & 0.01 & -0.08 & $0.09(0.00$ to 0.17$)$ & 0.046 \\
\hline Part 2, visual analogue scale & -3.8 & -4.2 & $0.4(-6.7$ to 7.5$)$ & 0.92 \\
\hline Activity count, no. per day† & -8168 & -15819 & 7651 (-1 137 to 26672$)$ & 0.43 \\
\hline
\end{tabular}

Note: $\mathrm{Cl}=$ confidence interval, NEADL = Nottingham Extended Activities of Daily Living, EQ-5D = EuroQol 5-domain questionnaire on health-related quality of life (see Methods for details).

*Lower scores indicate improvement.

†Measured with a tri-axial accelerometer worn during waking hours (see Methods for details). 
The outcome measures used in our study reflect the demands of everyday life in elderly people. Our study is limited by the fact that only about one-quarter of the patients screened were eligible for inclusion in the study. However, because more than $46 \%$ of those not eligible were already receiving an ACE inhibitor or an angiotensin II receptor blocker, our findings may be generalizable to a larger population. The fact that only $20 \%$ of those eligible participated in the trial is not unusual in the population studied. ${ }^{35}$ Another limitation is that, although our study was powered to detect a $20-\mathrm{m}$ change in 6-minute walking distance, it was probably too small to detect significant differences in other outcome measures. Also, for the secondary outcome measures, we did not carry out adjustments for multiple testing because there is no agreement as to the best way of achieving this for outcomes that are related to each other.

\section{Conclusion and future research}

Perindopril was found not only to improve physical function, as reflected by an increase in exercise capacity, but also to prevent deterioration in health-related quality of life in functionally impaired elderly people. Further studies with longer follow-up are required to assess the full magnitude of the benefits achieved with the use of ACE inhibitors. Clinicians deliberating over the use of ACE inhibitors in elderly people for existing indications may be further encouraged to do so given the beneficial effects on exercise capacity and quality of life observed in this study.

\section{This article has been peer reviewed.}

Competing interests: None declared.

Contributors: Deepa Sumukadas participated in the study recruitment, data collection, analysis and interpretation, and the writing of the manuscript. Miles Witham, Allan Struthers and Marion McMurdo participated in the study design, recruitment, data analysis and interpretation, and the writing of the manuscript. Allan Struthers conceived the initial idea for the project. Marion McMurdo is responsible for the overall content as the guarantor for the paper.

Acknowledgements: We thank the patients who participated in the study. We also thank Dr. Fergus Daly for statistical advice.

Perindopril was supplied free of charge by Servier Laboratories, Slough, UK. The study was funded by the Chief Scientist Office, Scottish Executive Department of Health; the Chief Scientist Office had no role in the study design, the collection, analysis or interpretation of the data, the writing of the report, or the decision to submit the paper for publication.

\section{REFERENCES}

I. Henriksen EJ, Jacob S. Modulation of metabolic control by angiotensin converting enzyme (ACE) inhibition. J Cell Physiol 2003;196:I7I-9.

2. Onder G, Penninx BW, Balkrishnan R, et al. Relation between use of angiotensinconverting enzyme inhibitors and muscle strength and physical function in older women: an observational study. Lancet 2002;359:926-30.

3. Montgomery $\mathrm{H}$, Clarkson $\mathrm{P}$, Barnard $\mathrm{M}$, et al. Angiotensin-converting-enzyme gene insertion/deletion polymorphism and response to physical training. Lancet I999;353:54I-5.

4. Hutcheon SD, Gillespie ND, Crombie IK, et al. Perindopril improves six minute walking distance in older patients with left ventricular systolic dysfunction: a randomised double blind placebo controlled trial. Heart 2002;88:373-7.

5. Remme WJ, Swedberg K. Comprehensive guidelines for the diagnosis and treatment of chronic heart failure. Task force for the diagnosis and treatment of chronic heart failure of the European Society of Cardiology. Eur J Heart Fail 2002;4:II-22.

6. McGowan JH, Cleland JG. Reliability of reporting left ventricular systolic function by echocardiography: a systematic review of 3 methods. Am Heart J 2003;I46:388-97.

7. Enright PL, McBurnie MA, Bittner V, et al. The 6-min walk test: a quick measure of functional status in elderly adults. Chest 2003;123:387-98.
8. O'Keeffe ST, Lye M, Donnellan C, et al. Reproducibility and responsiveness of quality of life assessment and six minute walk test in elderly heart failure patients. Heart $1998 ; 80: 377-82$.

9. Nelson ME, Layne JE, Bernstein MJ, et al. The effects of multidimensional homebased exercise on functional performance in elderly people. J Gerontol A Biol Sci Med Sci 2004;59:154-60.

Io. Lord SR, Castell S, Corcoran J, et al. The effect of group exercise on physical functioning and falls in frail older people living in retirement villages: a randomized, controlled trial. JAm Geriatr Soc 2003;51:1685-92.

II. Csuka M, McCarty DJ. Simple method for measurement of lower extremity muscle strength. Am J Med ig85;78:77-8r.

12. Shumway-Cook A, Brauer S, Woollacott M. Predicting the probability for falls in community-dwelling older adults using the Timed Up \& Go Test. Phys Ther 2000 80:896-903.

13. Podsiadlo D, Richardson S. The timed "Up \& Go": a test of basic functional mobility for frail elderly persons. J Am Geriatr Soc I991;39:I42-8

I4. Nordin E, Rosendahl E, Lundin-Olsson L. Timed "Up \& Go" test: reliability in older people dependent in activities of daily living - focus on cognitive state. Phys Ther 2006;86:646-55.

I5. Kochersberger G, McConnell E, Kuchibhatla MN, et al. The reliability, validity, and stability of a measure of physical activity in the elderly. Arch Phys Med Rehabil I996;77:793-5.

r6. Nouri FM, Lincoln NB. An extended activities of daily living scale for stroke patients. Clin Rehabil I987;1:30I-5.

I7. Harwood RH, Ebrahim S. The validity, reliability and responsiveness of the Nottingham Extended Activities of Daily Living scale in patients undergoing total hip replacement. Disabil Rehabil 2002;24:37I-7.

I8. Rabin R, de Charro F. EQ-5D: a measure of health status from the EuroQol Group. Ann Med 2001;33:337-43.

I9. Yusuf S, Sleight P, Pogue J, et al. Effects of an angiotensin-converting-enzyme inhibitor, ramipril, on cardiovascular events in high-risk patients. The Heart Outcomes Prevention Evaluation Study Investigators [published errata in $N$ Engl J Med 2000;342:748 and 2000;342:1376]. N Engl J Med 2000;342:I45-53.

20. Perera S, Mody SH, Woodman RC, et al. Meaningful change and responsiveness in common physical performance measures in older adults. J Am Geriatr Soc 2006;54:743-9.

2I. Lord SR, Castell S, Corcoran J, et al. The effect of group exercise on physical functioning and falls in frail older people living in retirement villages: a randomized, controlled trial. J Am Geriatr Soc 2003;51:1685-92.

22. Walters SJ, Brazier JE. Comparison of the minimally important difference for two health state utility measures: EQ-5D and SF-6D. Qual Life Res 2005;I4:I523-32.

23. Perera S, Studenski S, Chandler JM, et al. Magnitude and patterns of decline in health and function in I year affect subsequent 5-year survival. J Gerontol A Biol Sci Med Sci 2005;60:894-900.

24. Schrag A, Selai C, Jahanshahi M, et al. The EQ-5D - a generic quality of life measure - is a useful instrument to measure quality of life in patients with Parkinson's disease. J Neurol Neurosurg Psychiatry 2000;69:67-73.

25. Latham NK, Bennett DA, Stretton CM, et al. Systematic review of progressive resistance strength training in older adults. J Gerontol A Biol Sci Med Sci 2004;59:48-6I.

26. Eu JP, Hare JM, Hess DT et al. Concerted regulation of skeletal muscle contractility by oxygen tension and endogenous nitric oxide. Proc Natl Acad Sci USA 2003; ;00: I5229-34.

27. Koh TJ, Tidball JG. Nitric oxide synthase inhibitors reduce sarcomere addition in rat skeletal muscle. J Physiol I999;519:I89-96.

28. Wang MX, Murrell DF, Szabo C, et al. Nitric oxide in skeletal muscle: inhibition of nitric oxide synthase inhibits walking speed in rats. Nitric Oxide 200I;5:219-32.

29. Di Bari M, van de Poll-Franse LV, Onder G, et al. Antihypertensive medications and differences in muscle mass in older persons: the Health, Aging and Body Composition Study. J Am Geriatr Soc 2004;52:96I-6.

30. Vescovo G, Dalla LL, Serafini F, et al. Improved exercise tolerance after losartan and enalapril in heart failure: correlation with changes in skeletal muscle myosin heavy chain composition. Circulation 1998;98:1742-9.

3I. Lonn E, Shaikholeslami R, Yi Q, et al. Effects of ramipril on left ventricular mas and function in cardiovascular patients with controlled blood pressure and with preserved left ventricular ejection fraction: a substudy of the Heart Outcomes Prevention Evaluation (HOPE) Trial. J Am Coll Cardiol 2004;43:2200-6.

32. Coirault $\mathrm{C}$, Langeron $\mathrm{O}$, Lambert $\mathrm{F}$, et al. Impaired skeletal muscle performance in the early stage of cardiac pressure overload in rabbits: beneficial effects of angiotensin-converting enzyme inhibition. J Pharmacol Exp Ther I999;291:70-5.

33. Newman AB, Gottdiener JS, Mcburnie MA, et al. Associations of subclinical cardiovascular disease with frailty. J Gerontol A Biol Sci Med Sci 200I;56:Mr58-66.

34. Ahimastos AA, Lawler A, Reid CM, et al. Brief communication: ramipril markedly improves walking ability in patients with peripheral arterial disease: a randomized trial. Ann Intern Med 2006; I44:660-4.

35. Allsup SJ, Gosney MA. Difficulties of recruitment for a randomized controlled trial involving influenza vaccination in healthy older people. Gerontology 2002;48:170-3.

Correspondence to: Dr. Deepa Sumukadas, Medicine for the Elderly, NHS Tayside, Section of Ageing and Health, Ninewells Hospital and Medical School, Dundee DDI gSY, UK; fax or382 660675; d.sumukadas@nhs.net 